\title{
Overweight and Obesity before, during and after Pregnancy
}

Part 2: Evidence-based Risk Factors and Interventions

\author{
Übergewicht und Adipositas in der Peripartualperiode \\ Teil 2: Evidenzbasierte Untersuchungen der Risiken und Interventionen
}

Authors

Affiliations
B. Arabin ${ }^{1,2,3}$, J. H. Stupin ${ }^{1,3}$

${ }^{1}$ Clara Angela Foundation, Witten and Berlin

2 Phillips University Marburg, Centre for Mother and Child

${ }^{3}$ Department of Obstetrics, University Hospital Charité Berlin

\author{
Key words \\ - obesity during pregnancy \\ - metabolic syndrome \\ - diabetes \\ prevention \\ Schlüsselwörter \\ - Adipositas in der \\ Schwangerschaft \\ - Metabolisches Syndrom \\ - Diabetes \\ - Prävention
}

Deutschsprachige Zusatzinformationen online abrufbar unter: www.thieme-connect.de/ ejournals/toc/gebfra

\begin{abstract}
received 12.3.2014
revised $\quad 7.4 .2014$

accepted 10.4.2014
\end{abstract}

Bibliography

DOI http://dx.doi.org/

10.1055/s-0034-1368462

Geburtsh Frauenheilk 2014; 74 :

646-655 (c) Georg Thieme

Verlag KG Stuttgart · New York .

ISSN 0016-5751

\section{Correspondence}

Prof. Dr. Birgit Arabin

Clara Angela Foundation

A. Herrhausen Straße 44

58455 Witten

bine.clara.angela@gmail.com

\section{Abstract \\ $\nabla$}

Overweight and obesity have become a global health problem. Obesity and excessive weight gain during pregnancy have a serious impact on maternal, fetal and neonatal outcomes. Pre-conceptional obesity and excessive weight gain during pregnancy are associated with weight gain in women following childbirth leading to associated risks such as metabolic syndrome, cardiovascular disease and diabetes. Long-term risks for the offspring are an increased risk for early cardiovascular events, metabolic syndrome and decreased life expectancy as adults. German health care has not yet adequately responded to this development. There are no clinical guidelines for obesity before, during or after pregnancy, there are no concerted actions amongst midwives, obstetricians, health advisors, politicians and the media. Research projects on effective interventions are lacking although health care concepts would be urgently needed to reduce future metabolic and cardiovascular risks for women and children as well as to minimize the associated costs for the society.

\section{Introduction}

$\nabla$

Overweight and obesity have become epidemic in industrialized nations and even in developing countries $[1,2]$. Obstetric care givers should be concerned about the increased rate of maternal complications and mortality, the immediate risks for fetus and newborn, the long-term effects on women's health and the life expectancy of future generations.

Ad 1) Overweight or obesity increase the rate of maternal complications and of maternal mortal-

\section{Zusammenfassung \\ $\nabla$}

Adipositas ist inzwischen ein globales gesundheitliches Problem. Adipositas und starke Gewichtszunahme in der Schwangerschaft haben in Industrieländern zu einer Zunahme von Komplikationen während der Gravidität geführt, die mütterliches und kindliches Outcome beeinträchtigen. Nicht nur die präkonzeptionelle Adipositas, sondern auch die übermäßige Gewichtszunahme während der Gravidität sind verantwortlich für eine Gewichtszunahme von Frauen nach der Geburt sowie den assoziierten Risiken wie metabolisches Syndrom, kardiovaskuläre Erkrankungen und Diabetes, aber auch für Langzeitrisiken der Kinder wie Adipositas, höhere Morbidität und frühere Sterblichkeit als Erwachsene. In Deutschland hat man bisher nicht adäquat auf diese Entwicklung reagiert - es gibt weder klinische Richtlinien für die Schwangerschaft, noch konzertierte Aktionen von Hebammen, Geburtsmedizinern, Gesundheitsberatern, Politik und Medien. Untersuchungsprojekte über effektive Interventionen fehlen. Dies alles wäre jedoch erforderlich, um die gesundheitlichen Risiken für Frauen und Kinder sowie die damit verbundenen Kosten für das Gesundheitssystem und letztlich für unsere Gesellschaft einzuschränken.

ity. Between 2003 and 2005, more than 50\% of maternal deaths in the UK were associated with overweight or obesity [3]. Unfortunately, the aetiology and risk factors of maternal deaths are not evaluated in Germany, but there seems to be a similar trend.

Ad 2) Pre-conceptional obesity is associated with an increased rate of congenital defects, regardless of the malformations which are difficult to recognize [4]. According to a British cohort study of 287213 pregnancies, the risk of stillbirth increases from 4/1000 with a normal BMI to 6.9/ 
Table 1 Key to evidence statements and grading of recommendations, using the ranking of the Canadian Task Force on Preventive Health Care.[13].

\section{Criteria}

I: Evidence obtained from at least one properly randomized controlled trial II-1: Evidence from well-designed controlled trial without randomization II-2: Evidence from well-designed cohort (prospective or retrospective) or case-control studies, preferably from more than one centre or research group

II-3: Evidence obtained from comparisons between times or places with or without the intervention. Dramatic results in uncontrolled experiments (such as the results of treatment with penicillin in the 1940 s) could also be included in this category

III: Opinions of respected authorities, based on clinical experience, descriptive studies, or reports of expert committees

\section{Measures}

A. There is good evidence to recommend the clinical preventive action B. There is fair evidence to recommend the clinical preventive action C. The existing evidence is conflicting and does not allow to make a recommendation for or against use of the clinical preventive action; however, other factors may have an influence on decision-making

D. There is fair evidence to recommend against the clinical preventive action E. There is good evidence to recommend against the clinical preventive action

L. There is insufficient evidence (in quantity or quality) to make a recommendation; however, other factors may influence decision-making

Table 2 Weight classification/WHO [17], with modified criteria of the Canadian guidelines [13] and recommended weight gain according to the Institute of Medicine (IOM) [19], commented by Rasmussen [18, 40].

\begin{tabular}{|lllll}
\hline Criteria & BMI $\left(\mathbf{k g} / \mathbf{m}^{2}\right)$ & $\begin{array}{l}\text { Recommended weight gain } \\
\text { Course of pregnancy } \\
\text { Singleton pregnancy }\end{array}$ & $\begin{array}{l}\text { Twin pregnancy } \\
\text { no information }\end{array}$ & $\begin{array}{l}\text { 2nd and 3rd trimester } \\
\text { Singleton pregnancy }\end{array}$ \\
\hline Underweight & $<18,5$ & $12.5-18 \mathrm{~kg}$ & $17-25 \mathrm{~kg}$ & $0.51(0.44-0.58) \mathrm{kg} / \mathrm{gestational} \mathrm{week}$ \\
\hline Normal weight & $18.5-24.9$ & $11.5-16 \mathrm{~kg}$ & $14-23 \mathrm{~kg}$ & $0.28(0.23-0.50) \mathrm{kg} / \mathrm{gestational} \mathrm{week}$ \\
\hline Overweight & $25-29.9$ & $7-11.5 \mathrm{~kg}$ & $11-19 \mathrm{~kg}$ & $0.22(0.17-0.27) \mathrm{kg} / \mathrm{gestational}$ week \\
\hline Obesity class I & $30-34.9$ & $5-9 \mathrm{~kg}$ & $11-19 \mathrm{~kg}$ & $0.22(0.17-0.27) \mathrm{kg} / \mathrm{gestational} \mathrm{week}$ \\
\hline Obesity class II & $35-39.9$ & $5-9 \mathrm{~kg}$ & $11-19 \mathrm{~kg}$ & $0.22(0.17-0.27) \mathrm{kg} / \mathrm{gestational} \mathrm{week}$ \\
\hline Obesity class III & $>40$ & $5-9 \mathrm{~kg}$ & &
\end{tabular}

1000 with a BMI > 30, even after adjusting for diabetes, pre-eclampsia, maternal age, parity or nicotine abuse [5]. In a metaanalysis, the risk was judged to be twice as high [6]. A dramatic increase in prenatal mortality has been observed in the case of a combination of poor fetal growth and a maternal BMI $>25$ with an odd ratio (OR) of 75 , and a $95 \%$ confidence interval (CI) of 14-350 [7]. Furthermore, (iatrogenic) prematurity and the risk of neonatal injuries and hypoglycaemia are increased.

Ad 3) Pregnant women with a high BMI have an increased risk of metabolic syndrome [8], type 2 diabetes and cardiovascular disease in their later life [9].

Ad 4) As concluded from 37709 birth records from 1950 up to now, cause mortality was increased in offspring of obese mothers (BMI > 30) compared with mothers with normal BMI even after adjustment for maternal age at delivery, socioeconomic status, sex of offspring, current age, birth weight, gestation at delivery, and gestation at measurement of BMI (OR 1.35, 95\% CI 1.171.55). Adult offspring of obese mothers also had an increased risk of hospital admission for a cardiovascular event and a higher risk of adverse outcomes [10]. They also suffer from health problems in early life, even after adjusting for age, socioeconomic status, gender, birth weight and gestational age at birth [11]. Similarly, "programming of a shortened life" was found in the offspring of animals who were exposed to a high caloric diet during pregnancy whereby the effect could be reversed by "exercise" [12]. This overview is alarming. Although there is a German guideline on gestational diabetes of more than 90 pages, there is no guideline on how to prevent or treat obesity during pregnancy, although it is combined with a higher risk for subsequent metabolic syndrome than gestational diabetes [8].
We therefore have accepted the invitation to write this review integrating the expertise from guidelines used in Canada, the US, the UK and the Netherlands ( Table 1) [13-16].

\section{Pre-conceptional Obesity/Interventions}

$\nabla$

\section{Definition}

Obese patients suffer from an elevated body mass index (BMI) which is defined as weight/height $\left(\mathrm{kg} / \mathrm{m}^{2}\right)$. The WHO classifications and corresponding recommendations for weight gain are shown in Table 2 [17-19]; recommendations for patients with a BMI greater than 35 are not yet completely based on clear evidence [18]. Women should set pregnancy weight gain goals based on their pre-pregnancy BMI or the BMI during the first antenatal visit.

Ethnic differences exist [20]. The physiologic increase of BMI during pregnancy in about $50 \%$ of women caused by an increase of intra- and extravascular fluid cannot be used as an indicator of body fat [13]. In 2009, the Institute of Medicine (IOM) in the US revised the pregnancy recommendations not regarding ethnicity, age, smoking behaviour and parity ( $\bigcirc$ Table 2) [19]. Trimesterspecific recommendations for weight gain were defined and evidence-based absolute and relative risks (RR) for mother and child were finally used for recommendations [21]. Morbid obesity identifies patients with a BMI of $>40 \mathrm{~kg} / \mathrm{m}^{2}$. Other definitions refer to a weight that is $50-100 \%$ above the ideal weight.

In new guidelines, waist circumference and co-morbidity are used as criteria for weight reduction in obese non-pregnant patients. Regardless of the BMI, women who followed the weight gain guidelines ( Table 2 ) had fewer adverse outcomes (Caesar- 
ean delivery, gestational hypertension, birth weight $<2500 \mathrm{~g}$ or $>4000 \mathrm{~g}$ ) [13].

Unfortunately, the identification of women at risk is not routinely followed by interventions. Suggested strategies include behavioural weight loss treatment and counselling regarding exercise, diet, and pregnancy weight gain. So far, no diet offers clear advantages [22]. Early counselling by paediatricians, general practitioners, at schools and universities should be promoted. In adolescents between 11 and 15 years of age, a good breakfast and physical activity were the main negative predictors for obesity [23].

\section{Pre-conceptional counselling/interventions}

It is critical that women are informed prior to pregnancy about the need to be as healthy as possible before becoming pregnant, which includes having a normal BMI, eating a balanced diet, and participating in regular exercise. According to international guidelines it is encouraged that overweight and obese women who are planning a pregnancy should be referred to pre-conception assessment and counselling (II-B). Weight reduction is essential prior to infertility treatment (I-A). A pregnancy should only be considered with a BMI $<30$, and ideally with a BMI $<25 \mathrm{~kg} /$ $\mathrm{m}^{2}$ (I-B). In comparison to women of normal weight, women with a BMI > 50 are at risk of pregnancy-induced hypertension (19.7 vs. $4.8 \%$, OR 1.56; $95 \%$ CI 1.33-1.82), gestational diabetes (21.1 vs. $1.5 \%$, OR 2.04 ; $95 \%$ CI $1.74-2.38$ ), shoulder dystocia (7.1 vs. $1.4 \%$, OR 1.51; $95 \%$ CI 1.05-2.19), Caesarean delivery (60.6 vs. $25.0 \%$, OR 1.46; 95\% CI 1.29-1.65), long duration of hospital stay (14.3 vs. $4.7 \%$, OR $1.42 ; 95 \%$ CI $1.07-1.89$ ), child's birth weight $\geq 4000 \mathrm{~g}$ (38.0 vs. $11.9 \%$, OR $1.58 ; 95 \% \mathrm{Cl} 1.38-1.80$ ) or $\geq 4500 \mathrm{~g}$ (16.9 vs. $2.1 \%$, OR $1.87 ; 95 \%$ CI $1.57-2.23$ ), for neonatal metabolic problems (8.5 vs. $2.0 \%$, OR $1.50 ; 95 \% \mathrm{CI} 1.20-1.86$ ), for admission of the child (16.9 vs. $7.8 \%$, OR $1.28 ; 95 \% \mathrm{CI} 1.07-1.52)$ or stillbirth (1.4 vs. $0.2 \%$, OR $1.68 ; 95 \%$ CI $1.00-2.82$ ) (I) [24]. Long-term maternal risks include osteoarthritis, malignant disease and sleep apnoea. These risks can be limited by regular exercise (II-B) [11]. Nutrition consultation should be offered prior to conception [25]. Women with a BMI > 50 frequently smoke (II-2) [26] but vice versa, women who stop smoking are at an increased risk of weight gain [27].

\section{First Trimester Risks/Impact for Clinical Practice $\nabla$}

\section{Risk of miscarriage}

The risk of spontaneous abortion is higher in obese women compared to pregnant women with a normal BMI (OR 3.98; $95 \% \mathrm{CI}$, 1.06-14.92). However, no significant differences have been found in overweight pregnant women (OR 1.02; 95\% CI 0.72-1.45) [28]. The risk of miscarriage increases from $13.3 \%$ in normal weight to $38.7 \%$ in obese women (I) [29]. The association between obesity and increased rates of spontaneous abortion (OR 1.2, 95\% CI 1.01-1.46) and recurrent (>3) early miscarriages (OR 3.5, 95\% CI 1.03-12.01) have been described by a retrospective case-control study (II-2) [18]. Several cohort studies have shown that overweight and obese women have a higher risk of miscarriage in patients with infertility treatment (I) [29-31].

\section{Malformations}

The rate of malformations is increased in pregnancies of overweight and obese mothers. Although most malformations develop during the first trimester, they are frequently diagnosed at an advanced stage of pregnancy, or even post partum due to decreased visibility [32]. Women with a high BMI are at increased risk for neural tube defects (NTD) even after adjusting for diabetes with an OR of 1.22 (95\% CI 0.99-1.49), 1.70 (95\% CI 1.34-2.15) and 3.11 (95\% CI 1.75-5.46) for overweight, obese and severely obese women compared with women and normal BMI (II-1) [33-35].

\section{Interventions}

Obese pregnant women should be counselled with regard to diet, supplements, exercise, and weight gain (II-2-B). Compared to women with a BMI $<27$, women with a BMI $\geq 27$ have lower serum folate levels even after controlling for folate intake (II) suggesting that obese women should receive higher doses of folate supplementation in order to minimize the risk of fetal NTD. It is uncertain to what extent folic acid $>400$ micrograms has a beneficial effect on reducing congenital malformations (III-C) [35].

Pre-pregnancy BMI is inversely associated with serum vitamin D concentrations in pregnant women. Health professionals should therefore check that women with a booking BMI > 30 take 10 micrograms Vitamin D supplementation daily during pregnancy and while breastfeeding (III-C) [15].

Women should set pregnancy weight gain goals based on the BMI as shown in $\mathbf{0}$ Table $\mathbf{2}$ at their first antenatal visit. In addition, they should be advised that regular exercise reduces future risks for herself and the offspring unless there are contraindications (II-1-B) [36]. Right from the first visits women can be questioned and advised about their diet and if the BMI is $>30$ they should be screened for gestational diabetes already at the first visit [15]. Exercise habits and nutritional counselling can be a helpful adjunct for women not meeting the weight gain guidelines (I-B) [37]. In addition, they may be motivated by knowing that following these guidelines would reduce their risks for a Caesarean, hypertension and abnormal birth weights in their children [36]. Up to now, randomized trials on behavioural interventions in obese mothers have not been convincing [38] and a diet restricting protein and any energy intake should be avoided (IIIC) [39].

\section{Second and Third Trimester/Impact for Clinical Practice} $\checkmark$

Obesity is associated with an increased risk of a number of serious adverse outcomes during the second and third trimester including stillbirth, hypertension, pre-eclampsia and gestational diabetes. From the second trimester onwards, weekly weight gain can be used to predict total weight gain $[19,40]$ and, if necessary, to prompt interventions [41]. Re-assessment of maternal weight during the second and third trimester will allow to consider future risks and to make appropriate plans for equipment and personnel required during labour and delivery.

\section{Unexplained stillbirth}

Pre-pregnancy obesity is the most prevalent risk factor for unexplained stillbirth [42]. In women with a BMI > 35 the OR was 2.79 (95\% CI 1.94-4.02) compared to normal-weight women (II-1) [43]. To determine the risks of stillbirth after 22 gestational weeks, 96/6963 population-based studies were selected. A BMI $>25$ was the most significant risk factor (more than age and cigarette smoking) and contributed to around 8000 stillbirths per year in studies from 5 countries (II-1) [44]. In a recent Scandinavian study, these differences were less pronounced [45]. Reasons 
for the increased risk may include that fetal movements are not recognized, that hyperlipidaemia limits placental blood flow and that sleep apnoea could be associated with fetal hypoxia [46]. Pre-conceptional care and audits of perinatal deaths are steps towards reducing stillbirth rate in high-income countries (II-2-C) [47].

\section{Hypertension}

An appropriate size of arm cuff should be used for blood pressure measurements during all antenatal consultations. The cuff size used should be documented in the medical records (II-B) [48].

A retrospective study compared 79005 women stratified by maternal pre-pregnancy weight between 55 and $75 \mathrm{~kg}, 9355$ women between 90 and $120 \mathrm{~kg}$ (moderate obesity) and 779 women of more than $120 \mathrm{~kg}$ (severe obesity). The risk of pregnancy-induced hypertension rose significantly in moderate obesity: OR 2.38, 95\% CI 2.24-2.52 and severe obesity: OR 3.00, 95\% CI 2.493.62. Accordingly, obesity also increased the likelihood that women would experience severe hypertension and HELLP syndrome with an OR of 1.56, 95\% CI 1.35-1.8 in moderate obese and an OR of $2.34,95 \%$ CI 1.59-3.46 in severely obese women. One in every 10 moderately obese and in every 7 severely obese women had serious complications (II-2) [49]. These findings have been confirmed by a prospective study with $>2000$ (seriously) obese women (II-1) [50].

\section{Gestational diabetes}

Maternal obesity is known to be an important risk factor for gestational diabetes (GDM) with a number of large cohort studies reporting a three-fold increased risk compared to women with a healthy weight [15]. In women with a BMI > 35 the OR was 2.6, 95\% CI 2.1-3.4, and increased to an OR of 4.0, 95\% CI 3.1-5.2 in women with a BMI>40 compared to women with a BMI <30 (II-2) [50]. This also increased the risk for children > $4000 \mathrm{~g}$ : OR 1.7, 95\% CI 1.4-2.0, for obese mothers: OR 2.0, 95\% CI 1.5-2.3, for very obese pregnant women and for children $>4500 \mathrm{~g}$ : OR 2.0, 95\% CI 1.4-3.0 and OR 2.4, 95\% CI 1.5-3.8 (II-1) [29].

\section{Malformations and ultrasound}

The ability to evaluate fetal structures is largely dependent on maternal size. Approximately $15 \%$ of normally visible structures will be suboptimally seen in women with a BMI above the 90th percentile; in women with a BMI above the 97.5th percentile, only two thirds of structures are well visualized. As a result, repeat examinations 2 to 4 weeks later or second opinion examinations will reduce the number of poorly viewed fetuses; however, up to $20 \%$ (depending on BMI class) will remain poorly visualized [52]. Obstetric care providers consider the BMI when arranging for fetal anatomic assessment, since there is a two-fold increase in the rate of NTD in children of mothers with a high BMI $[53,54]$ and an increased rate of cardiac malformations, abdominal wall defects, cleft lips and cleft palates [53].

\section{Twin pregnancy}

According to a population-based cohort study, a high BMI and excessive weight gain during pregnancy ( $\bullet$ Table 2 ) are associated with poorer outcomes in twin pregnancies [55]. In a French cohort study of 514 twin pregnancies, obese mothers reported an increased rate of pregnancy-induced hypertension (34.1\% vs. $17.9 \%, \mathrm{p}=0.011)$, pre-eclampsia ( $27.3 \%$ vs. $14.4 \%, \mathrm{p}=0.028)$ and gestational diabetes $(22.2 \%$ vs. $4.7 \%, \mathrm{p}<0.001)$ compared to mothers of normal weight (II-2) [56].
Interventions in the second and third trimester

Retrospective cohort studies have shown a $24-60 \%$ reduction in pre-eclampsia in nulliparous women who had increasing levels of exercise both in the year prior to conception and during the pregnancy (II-1) $[43,44]$. The protective mechanisms include enhanced placental growth and vascularity, prevention and reduction of oxidative stress and correction of vascular endothelial function [45]. Exercise reduces medical problems of diabetes - also during pregnancy. More relevant, a $34 \%$ reduction in the development of gestational diabetes was reported in obese women who did not participate in vigorous exercise but who did participate in brisk walking compared to easy pace walking [47]. Dietary advice should potentially be continued in relation to gestational diabetes and weight gain. Social stress factors should be discussed and support should be offered appropriately.

\section{Risks and Interventions during Delivery \\ $\nabla$}

Overweight and obese pregnant women have an increased rate of Caesarean delivery, shoulder dystocia, problems of anaesthesia, blood loss, thromboembolism and impaired wound healing. Antenatal consultation of pregnant women with a BMI $>30$ should be performed and documented. Delivery in a perinatal centre is indicated, as children of obese mothers are more likely to require neonatal intensive care (II-C) $[57,58]$.

\section{Caesarean section and Vaginal Birth \\ after Caesareans (VBAC)}

The risk of Caesarean delivery is increased in obese parturients as analyzed in 24423 nulliparous women stratified by pre-pregnancy BMI and pregnancy complications. The Caesarean rate was $14.3 \%$ for lean women with a BMI < 19.8, $26.5 \%$ in women with a BMI of 20-25, 32.8\% in women with a BMI between 25 and 30 , and $42.6 \%$ in women with a BMI $>35$. The risk of Caesareans rose gradually even in women without any other complications: OR 1.4, 95\% CI 1.0-1.8 (BMI of 25-29.9), OR 1.5, 95\% CI 1.1-2.1 (BMI 30-34.9) and OR 3.1, 95\% CI 2.3-4.8 (BMI $\geq 35$ ) [3]. Other studies have shown similar results $[29,59]$.

The increase in the rate of Caesarean deliveries may be partly due to the fact that overweight and obese nulliparous women progress more slowly through the first stage of labour. Obstetricians might be afraid of legal consequences of shoulder dystocia during a vaginal (operative) delivery, although its rate is even lowered in one study [60]. The clinical assessment of progression during vaginal delivery is more complex in obese women. If fully dilatation is achieved, transperineal ultrasound allowing to determine the "angle of progression" can facilitate the indication for vaginal (operative) delivery or in other words prevent a Caesarean delivery [61] (III-B), which is combined with high risks of prolonged operative time and wound healing, increased blood loss, endometritis despite antibiotic prophylaxis and thromboembolism $[62,63]$. Wound infection in women undergoing Caesareans is extremely common in obese women mainly if it is combined with gestational diabetes: OR 9.3, 95\% CI 4.5-19.2; women who require a vertical skin incision have a $12 \%$ rate of wound complications serious enough to require opening the incision [62,64]. Hospitals should ensure that the equipment of the operating theatre can accommodate obese parturients (appropriate instrumentation and operating tables).

Obese women are less likely to be successful in delivering vaginally after previous Caesarean delivery. In women with a BMI 
$<29$ the success rate was $54-68 \%[65,66]$; the rate is further reduced in heavier women - it was only $13 \%$ in women of $>136 \mathrm{~kg}$ [67].

In case of an emergency Caesarean delivery, the time from decision and from incision to delivery is prolonged due to a more complex set-up of anaesthesia and logistics. In case of a subcutaneous layer of $>2 \mathrm{~cm}$, the application of a subcutaneous suture is recommended (I-A) [68].

Some studies suggest that a Caesarean delivery is associated with an increased rate of diabetes and obesity of the child in later life, although these results are still debated $[69,70]$. A high maternal BMI and/or poor intrauterine growth are associated with obesity and type 2 diabetes in adulthood [71].

\section{Vaginal birth}

The increased rate of post-term pregnancies suggests that obesity is associated with impaired myometrial function [43]. In a retrospective cohort study in singleton pregnancies from the Danish Medical Birth Registry, women with a preconceptional BMI $>50$ required induction of labour more frequently than mothers with BMI $\leq 50: 38.4 \%$ vs. $13.2 \%$ with a RR of 2.91 and a $95 \%$ CI of 2.33-3.63. Requiring oxytocin during labour was also increased: RR 1.41, 95\% CI: 1.13-1.77 (II-1) [26]. Examination of the case records showed that the rate of emergency Caeesareans was nearly doubled ( $21 \%$ vs. $12 \%$ ).

The precise risks of secondary Caesareans depend on the knowledge and skills of the whole obstetric team how to balance oxytocin, encouragement and decisions during first and second stage of labour including the use of transperineal ultrasound.

In nulliparous women with spontaneous onset of labour and a high BMI, the first stage of labour is prolonged while the second stage may be shorter which should be considered for future protocols. External monitoring of fetal heart rate (FHR) and contractions is impaired and may require internal monitoring (III-C). Recently, electromyographic monitoring was performed in obese women showing a better recording quality compared to conventional tocography [72].

In a cohort of 126080 pregnancies without hypertension or diabetes obese women (BMI > 30) had an increased risk of fetal macrosomia with an OR of 1.4 (95\% CI 1.2 to 1.7) (II-1). Nevertheless, the risk for shoulder dystocia did not increase [73]. Similar results were found in another cohort [74].

It has been reported that the estimated fetal weight ( $>4000 \mathrm{~g}$, delivery within 3 days) was greater than the actual birth weight in $77 \%$ of obese women [75]. When fetal macrosomia was incorrectly predicted, the rate of Caesarean deliveries was significantly greater compared to normal fetal weight prediction: $42.3 \%$ versus $24.3 \%$, RR 1.74 (95\% CI, 1.09 to 2.78) (II-1) [76]. Although fetal macrosomia is a risk factor for shoulder dystocia, the absolute risk of a severe shoulder dystocia associated with permanent impairment or death, remains low. Considering the sensitivity and specificity of ultrasound to predict a birth weight $>4500$ g, 3695 non-diabetic women would have to undergo a Caesarean in order to prevent one plexus paralysis [77]!

Injuries of the maternal pelvic floor have not yet been studied with regard to maternal BMI and seem to depend rather on fetal size than on the phenomenon of obesity.

\section{Complications during delivery}

Both immobility and obesity are independent risk factors of thromboembolism; in combination, however, they may pose a much greater risk. This interaction has been demonstrated by a case-control study that reported an OR of 62.3 (95\% CI 11.5337.6) for antenatal venous thromboembolism (VTE) and 40.1 (95\% CI 8.0-201.5) for postnatal VTE in women with a BMI $\geq 25$ where there was evidence of immobilisation, compared with women with a BMI $<25$ and no immobilisation. In contrast, women with a BMI $\geq 25$ without evidence of immobilisation had a much lower OR of 1.8 (95\% CI 1.3-2.4) for antenatal VTE and 2.4 (95\% CI 1.7-3.3) for postnatal VTE [78].

A case-control study conducted in the United Kingdom reported that a BMI $\geq 30$ was associated with an OR of 2.65 (95\% CI 1.096.45) for antenatal pulmonary thromboembolism (PTE) (II) [15]. Obese women requiring pharmacological thromboprophylaxis should be prescribed appropriate doses of low molecular weight heparin (LMWH) according to national guidelines and additional risk factors and should be encouraged to mobilize as early as possible following childbirth (IIB) [15]. Women with a BMI $\geq 30$ who have two or more additional persisting risk factors should be given graduated compression stockings in addition to LMWH mainly in the case of immobilisation (III-C) [15].

Regardless of BMI, all women undergoing Caesarean delivery should be offered a single prophylactic dose of first generation cephalosporin or ampicillin to reduce postoperative infections (endometritis, urinary tract or wound infections) (I) and in obese women the dose should be adapted (IIIC).

Obese mothers have an increased risk of postpartum haemorrhage, post partum anaemia and the need for blood transfusion, therefore active management during the third stage of labour is recommended $[15,57]$.

\section{Obstetric anaesthesia}

Rates of difficult or failed intubation are increased in obese patients. A 6-year review of failed intubations in obstetric patients with an average BMI of 33 in a region of the United Kingdom reported 36/8970 (1/249) cases of failed intubation [79]. The equipment and expertise required to manage a difficult intubation should be readily available. In obese patients, also the risk of epidural failure is increased. The initial failure rate for epidural catheter placement was reported to be $42 \%$ [80]; multiple attempts at catheter placement may be required in up to $75 \%$ of very obese patients [62]. It is not yet clear, whether ultrasound diagnosis may facilitate the placement in these women [81]. According to a Danish cohort study, regional anaesthesia was impossible in $25 \%$ of all women with a BMI $>50$ [26]. In the case of failed epidural or spinal anaesthesia, the patient has to be treated with general anaesthesia; however, this is associated with elevated risks for both mother and child. Therefore, early epidural anaesthesia during the first stage of labour should be considered in order to avoid time delay in case of emergency (III-C).

\section{Postnatal Care and Follow-up after pregnancy \\ $\nabla$}

\section{Breastfeeding}

Obesity is associated with low breastfeeding initiation and maintenance rates $[82,83]$. Obese women should receive dedicated breastfeeding support regarding the benefits, initiation and maintenance of breastfeeding (II-2). Anatomical problems during breastfeeding and reduced prolactin levels could play a role why breastfeeding is more difficult [84]. Randomized trials have shown that prenatal breastfeeding support may increase the rate and duration of breastfeeding (I-A) [85]. Reduced cognitive abilities were demonstrated up to school age in the children of moth- 
ers with a BMI > 30; the mechanisms - and whether it is a reduced breastfeeding rate- are still unclear [86].

\section{Lifestyle interventions/surgical and pharmacological therapy}

A small number of randomized trials have assessed the effect of postnatal lifestyle interventions on weight reduction. Maternity services need to identify what services are available locally to provide this follow up. A Swedish population-based study of $>150000$ women examined the inter-pregnancy weight gain showing that an increased BMI in the second pregnancy was linearly correlated to the risk of pre-eclampsia, gestational diabetes, macrosomia, Caesarean delivery and stillbirth (II-2) [77].

An inter-pregnancy weight loss of $4.5 \mathrm{~kg}$ in $>4000$ mothers showed a reduction of gestational diabetes by $40 \%$ in the next pregnancy [78]. Women with a BMI $>30$ should be offered professional advice to modify dietary and physical activity leading to weight loss (I-A) [87-89]. Several systematic reviews of randomized and non-randomized trials [4] form the basis for evidence-based recommendations $[84,85]$. Diet and increased activity contribute to weight loss; diet alone bears the risk that fatfree tissue will be reduced, which is prevented with parallel activity [90]. Unfortunately, obese mothers are less aware of their pregnancy risks compared to women with gestational diabetes $(15.5$ vs. $75.0 \%, p<0.01)$ and are frequently not sufficiently informed about modifications of their lifestyles [91].

In a randomized trial ("lifestyle in pregnancy", LIP study), 360 obese pregnant women were offered life style interventions during pregnancy such as regular dietary counselling by trained dieticians and physical activity such as to be moderately active 30$60 \mathrm{~min} /$ day equipped with a pedometer, free full-time membership in a fitness centre with physiotherapists for $1 \mathrm{~h}$ each week. A total of $304(84 \%)$ women were followed up until delivery. The intervention group had a significantly lower gestational weight gain (GWG) compared with the control group of 7.0 (4.7-10.6) vs. $8.6 \mathrm{~kg}(5.7-11.5 ; \mathrm{p}=0.01)$. The IOM recommendations on GWG were exceeded in $35.4 \%$ of women in the intervention group compared with $46.6 \%$ in the control group ( $p=0.058$ ). Overall, the obstetric outcomes between the two groups were not significantly different [4].

Investigations during breastfeeding are lacking. A meta-analysis demonstrated that women with obesity and gestational diabetes have an increased risk of type-2 diabetes compared to women without gestational diabetes (I): RR 7.43, 95\% Cl 4.79-11.51 [92] until 5 years after birth [93].

Systematic reviews show that obese patients may benefit from surgical interventions such as bariatric or gastric bypass surgery [94]. Whether it can be concluded to recommend surgery for prepregnancy weight loss and to refer patients to pre-pregnancy surgery is contradictory. Patients should be informed that surgical (band dislocation, maternal bowel obstruction) and internal (nutrient deficiency, severe growth restriction) problems may arise during pregnancy [95]. After inserting a duodenal bypass between two pregnancies, some offspring showed reduced rates of obesity until puberty from $60 \%$ to $35 \%$ which was more pronounced in boys than in girls [96]. More recently, 340 followed children of 230 mothers who had undergone bariatric surgery showed no significant differences before and after maternal surgery; by 10 years of age, girls even had a higher weight compared to controls. Consequently, obese women should be informed risks and benefits (II-D) [97].
With regard to pharmacological treatment, a double blind study was performed on 564 non-pregnant patients with a BMI between 30 and 40 using different doses of the glucagon-like peptide- 1 receptor agonist liraglutide $(1.2 \mathrm{mg}, 1.8 \mathrm{mg}, 2.4 \mathrm{mg}$, and $3.0 \mathrm{mg}$ ) as well as orlistat and a placebo. All patients followed the same diet and fitness program. Weight loss in patients with liraglutide was more pronounced (up to $4.4 \mathrm{~kg}, 95 \%$ CI 2.9-6.0) compared to those taking the placebo and orlistat; $76 \%$ of patients taking $3 \mathrm{mg}$ liraglutide vs. $30 \%$ in the placebo group had a weight loss of more than $5 \%$. In addition, they had a lower blood pressure and the prevalence of pre-diabetes was reduced (I-A) [98]. It is currently investigated to what extent liraglutide may also prevent pre-diabetes (I) [99].

\section{Regional and national interventions}

The problems combined with obesity before, during and after pregnancy require guidelines at a local and national level [100]. The Royal College of Obstetrics and Gynaecology (RCOG) recommends that maternity units should have accessible multidisciplinary guidelines which are communicated to individuals and organisations providing care to pregnant women with a booking BMI $>30$. These guidelines should include facilities and equipment, care in pregnancy, place of birth and care in labour, provision of anaesthetic services, management of obstetric emergencies and postnatal follow-up.

In Germany, there are no systematic investigations with respect to the early diagnosis or interventions. There is not even a guideline. National campaigns and intervention strategies are urgently needed. It has been shown that maternal obesity is recognized as a public problem, but that counselling frequently fails if the counsellors are also overweight [101]. Increased parity, low income and insufficient education are associated with maternal obesity [102]. This makes efficient interventions more complex. Stigmatisation of patients should be avoided, but the consequences of further weight gain should be pointed out. Gynaecologists and midwives are inadequately trained for structured interviews and effective nutritional counselling [103]. A referral to a dietician might help to concentrate on diet and lifestyle, rather than only on weight gain. Even in countries with well-established guidelines, the required information is not provided to patients in more than $25 \%$ of cases [104]. Self-assessment is difficult, as $74 \%$ of obese women estimate their BMI to be lower and $64 \%$ the permitted weight gain to be higher [105]. A meta-analysis of 12 international studies showed that a so-called sugar-tax can lead to a weight reduction in the population (II-B) [106].

Public "campaigns" on TV and in social media could support the efforts of patients and their caregivers. In English-spoken media, there are already more than 1500 informative and interactive iTunes and Google Plays on the topic of pregnancy ("shared maternity care") [107]. Health care politicians could use these opportunities. Evidence-based interventions and respectful communication are essential since the costs may rise by around 2 trillion pounds annually in the US and England, and are expected to increase to more than 50 trillion pounds per year by 2020 [108]. Clinical admissions of overweight, obese and very obese women are increased by $16 \%, 45 \%$ and $88 \%$ respectively. The average additional costs during pregnancy were 350.75 (95\% CI £284.82416.69) pounds for women with a BMI > 40 (II-2) [108]. 


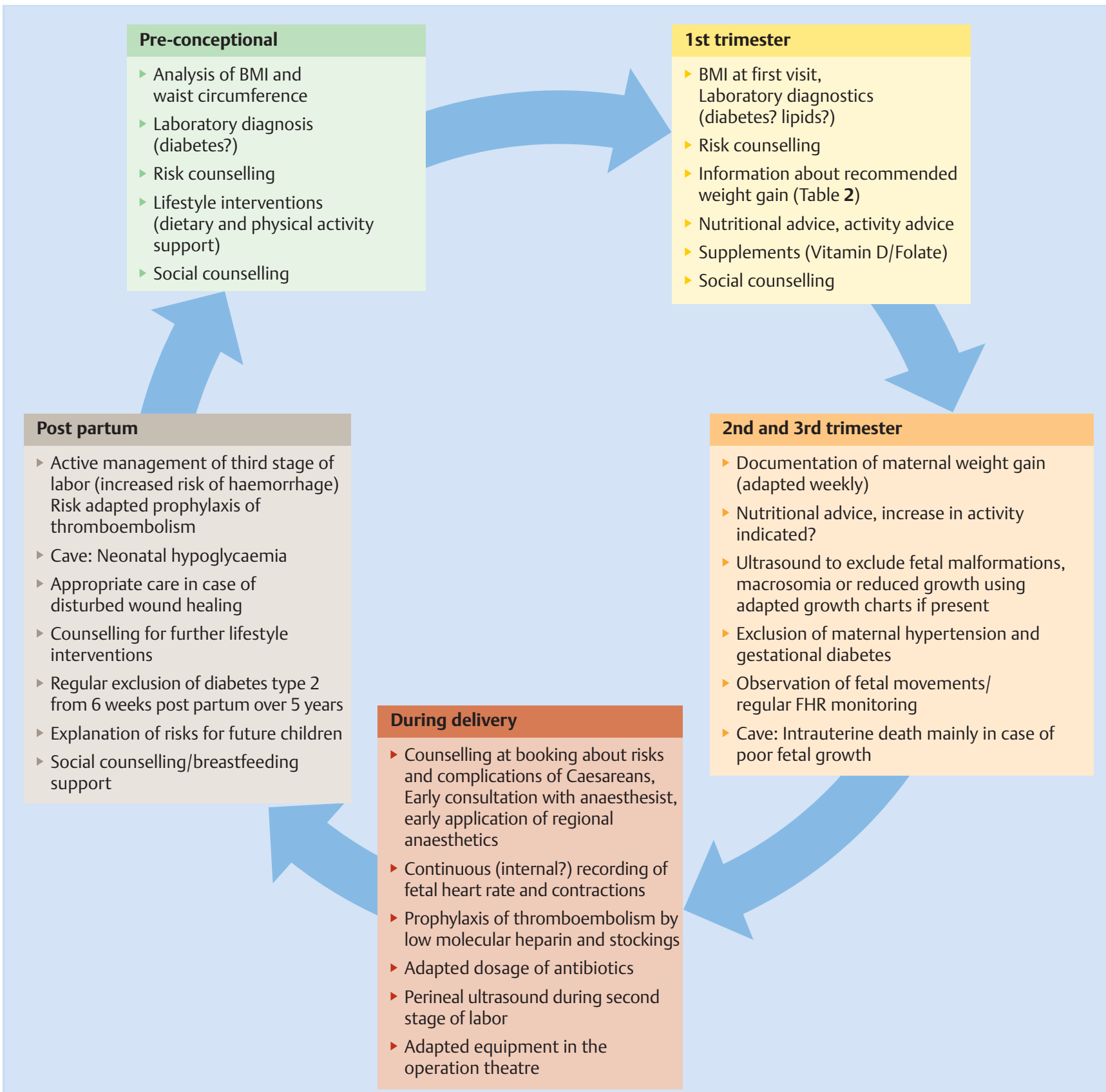

Fig. 1 Pragmatic flow chart of treatment of overweight and obese women pre-, peri- and postnatally.

\section{Conclusions for Clinical Practice}

\section{$\nabla$}

The time before, during and after pregnancy should be viewed a window of opportunities to minimize the short- and long-term health risks for women and their children at an early stage in their life span. Pragmatic proposals are suggested according to international studies ( $\bullet$ Fig. 1). No other pregnancy risk is associated with such a high rate of miscarriage and stillbirth. Both mother and child suffer irreversible short- and long-term risks. Obstetric medicine is a predominantly preventive discipline; otherwise it would be called obstetric surgery. It is doubtful whether efforts, which are offered by individual colleagues or professional organizations may (want to) cope with this problem. Therefore patients have to continue to rely on their own initiatives or to wait for social and political efforts, which usually take too much time since nobody invests in the virtual value of future health. Concerted actions of politicians, media, general practitioners, midwives and obstetricians are urgently needed as in other fields of our predominantly human, intellectual and preventive specialty with a view to future generation.

\section{Conflict of Interest \\ $\nabla$}

None. 


\section{References}

1 WHO. Global NCD Infobase. Geneva, Switzerland: World Health Organization; 2006

2 Flegal KM, Carroll MD, Kit BK et al. Prevalence of obesity and trends in the distribution of body mass index among US adults, 1999-2010. JAMA 2012; 307: 491-497

3 Dietz PM, Callaghan WM, Morrow B et al. Population-based assessment of the risk of primary cesarean delivery due to excess prepregnancy weight among nulliparous women delivering term infants. Matern Child Health J 2005; 9: 237-244

4 Vinter CA, Jensen DM, Ovesen P et al. The LiP (Lifestyle in Pregnancy) study: a randomized controlled trial of lifestyle intervention in 360 obese pregnant women. Diabetes Care 2011; 34: 2502-2507

5 Sebire NJ, Jolly M, Harris JP et al. Maternal obesity and pregnancy outcome: a study of 287,213 pregnancies in London. Int J Obes Relat Metab Disord 2001; 25: 1175-1182

6 Chu SY, Bachman DJ, Callaghan WM et al. Association between obesity during pregnancy and increased use of health care. N Engl J Med 2008; 358: $1444-1453$

7 Frøen JF, Gardosi JO, Thurmann A et al. Restricted fetal growth in sudden intrauterine unexplained death. Acta Obstet Gynecol Scand 2004; 83: 801-807

8 Ijäs H, Morin-Papunen L, Keränen AK et al. Pre-pregnancy overweight overtakes gestational diabetes as a risk factor for subsequent metabolic syndrome. Eur J Endocrinol 2013; 169: 605-611

9 Alberti KG, Zimmet P, Shaw J. The metabolic syndrome - a new worldwide definition. Lancet 2005; 366: 1059-1062

10 Reynolds RM, Allan KM, Raja EA et al. Maternal obesity during pregnancy and premature mortality from cardiovascular event in adult offspring: follow-up of 1323275 person years. BMJ 2013; 347: f4539

11 Salem SY, Kessous R, Pariente G et al. Obesity in pregnancy: what's next? Long-term cardiovascular morbidity in a follow-up period of more than a decade. Am J Obstet Gynecol 2014; 210 (1. Suppl.): S45, S68

12 Antony K, Ma J, Mitchell $\mathrm{K}$ et al. Excess gestational weight gain (GWG) is associated with alterations in metabolic function of the microbiome. Am J Obstet Gynecol 2014; 210 (1. Suppl.): S45, S69

13 Davies GA, Maxwell C, McLeod L et al.; Society of Obstetricians and Gynaecologists of Canada. SOGC Clinical Practice Guidelines: Obesity in pregnancy. No.239, February 2010. Int J Obstet Gynecol 2010; 32: $167-173$

14 ACOG Committee opinion no. 549: Obesity in pregnancy. Obstet Gynecol 2013; 121: 213-217

15 CMACE/RCOG Guideline. Management of women with obesity in pregnancy. Jointly published by the Centre for Maternal and Child Enquiries and the Royal College of Obstetricians and Gynaecologists. London: 2010

16 NVOG. Obesitas en zwangerschap. Online: www.nvog.nl; last access: 2009

17 WHO. Obesity: preventing and managing the global epidemic. WHO technical report series; 2000: 894

18 Rasmussen KM, Catalano PM, Yaktine AL. New guidelines for weight gain during pregnancy: what obstetrician/gynecologists should know. Curr Opin Obstet Gynecol 2009; 21: 521-526

19 Institute of Medicine (IOM). Weight gain during pregnancy: re-examining the guidelines. Committee to reexamine IOM pregnancy weight guidelines. Washington: National Research Council; 2009

20 Deurenberg P, Andreoli A, Borg P et al. The validity of predicted body fat percentage from body mass index and from impedance in samples of five European populations. Eur J Clin Nutr 2001; 55: 973-979

21 Viswanathan M, Siega-Riz AM, Moos MK. Outcomes of maternal weight gain. Evidence report/technology assessment, number 168 (AHRQ Publication No. 08-E09). Research Triangle Park, NC: RTI International-University of North Carolina Evidence-based Practice Center; 2008

22 Jensen MD, Ryan $D H$. New obesity guidelines: promise and potential. JAMA 2014; 311: 23-24

23 Haug E, Rasmusssen M, Samdal O et al.; HBSC Obesity Writing Group. Overweight in school-aged children and its relationship with demographic and lifestyle factors: results from the WHO-Collaborative Health Behaviour in School-aged Children (HBSC) study. Int J Public Health 2009; 54 (Suppl. 2): 167-179

24 Crane JM, Murphy P, Burrage L et al. Maternal and perinatal outcomes of extreme obesity in pregnancy. J Obstet Gynaecol Can 2013; 35: 606611
25 Olafsdottir AS, Skuladottir GV, Thorsdottir I et al. Maternal diet in early and late pregnancy in relation to weight gain. Int J Obes (Lond) 2006; 30: 492-499

26 Bonnesen B, Secker NJ, Møller LK et al. Pregnancy outcomes in a cohort of women with a preconception body mass index $>50 \mathrm{~kg} / \mathrm{m}(2)$. Acta Obstet Gynecol Scand 2013; 92: 1111-1114

27 Olafsdottir AS, Skuladottir GV, Thorsdottir I et al. Combined effects of maternal smoking status and dietary intake related to weight gain and birth size parameters. BJOG 2006; 113: 1296-1302

28 Metwally M, Saravelos SH, Ledger WL et al. Body mass index and risk of miscarriage in women with recurrent miscarriage. Fertil Steril 2010; 94: $290-295$

29 Bellver J, Rossal LP, Bosch E et al. Obesity and the risk of spontaneous abortion after oocyte donation. Fertil Steril 2003; 79: 1136-1140

30 Fedorcsák P, Storeng R, Dale PO et al. Obesity is a risk factor for early pregnancy loss after IVF or ICSI. Acta Obstet Gynecol Scand 2000; 79: 43-48

31 Wang JX, Davies MJ, Norman RJ. Obesity increases the risk of spontaneous abortion during infertility treatment. Obes Res 2002; 10: 551-554

32 Dashe JS, McIntire DD, Twickler DM. Effect of maternal obesity on the ultrasound detection of anomalous fetuses. Obstet Gynecol 2009; 113: $1001-1007$

33 Shaw GM, Velie EM, Schaffer $D$. Risk of neural tube defect-affected pregnancies among obese women. JAMA 1996; 275: 1093-1096

34 Waller DK, Mills JL, Simpson JL et al. Are obese women at higher risk for producing malformed offspring? Am J Obstet Gynecol 1994; 170: 541 548

35 Werler MM, Louik C, Shapiro S et al. Prepregnant weight in relation to risk of neural tube defects. JAMA 1996; 275: 1089-1092

36 Davies GA, Wolfe LA, Mottola MF et al. Exercise in pregnancy and the postpartum period. J Obstet Gynaecol Can 2003; 25: 516-529

37 Piirainen T, Isolauri E, Lagström H et al. Impact of dietary counselling on nutrient intake during pregnancy: a prospective cohort study. Br J Nutr 2006; 96: 1095-1104

38 Polley BA, Wing RR, Sims CJ. Randomized controlled trial to prevent excessive weight gain in pregnant women. Int J Obes Relat Metab Disord 2002; 26: 1494-1502

39 Kramer MS, Kakuma R. Energy and protein intake in pregnancy. Cochrane Database Syst Rev 2003; (4): CD000032

40 Rasmussen KM, Abrams B, Bodnar LM et al. Recommendations for weight gain during pregnancy in the context of the obesity epidemic. Obstet Gynecol 2010; 116: 1191-1195

41 Chmitorz A, von Kries R, Rasmussen KM et al. Do trimester-specific cutoffs predict whether women ultimately stay within the Institute of Medicine/National Research Council guidelines for gestational weight gain? Findings of a retrospective cohort study. Am J Clin Nutr 2012; 95: $1432-1437$

42 Fretts RC. Etiology and prevention of stillbirth. Am J Obstet Gynecol 2005; 193: 1923-1935

43 Cedergren MI. Maternal morbid obesity and the risk of adverse pregnancy outcome. Obstet Gynecol 2004; 103: 219-224

44 Flenady V, Koopmans L, Middleton P et al. Major risk factors for stillbirth in high-income countries: a systematic review and meta-analysis. Lancet $2011 ; 377$ : 1331-1340

45 Waldenström $U$, Aasheim V, Nilsen BV et al. Adverse pregnancy outcomes related to advanced maternal age compared with smoking and being overweight. Obstet Gynecol Clin North Am 2014; 123: 104-112

46 Thomas J, Paranjothy S, James D. National cross sectional survey to determine whether the decision to delivery interval is critical in emergency caesarean section. BMJ 2004; 328: 665

47 Flenady V, Middleton P, Smith GC et al. Stillbirths: the way forward in high-income countries. Lancet 2011; 377: 1703-1717

48 Maxwell MH, Waks AU, Schroth PC et al. Error in blood-pressure measurement due to incorrect cuff size in obese patients. Lancet 1982; 2: 33-36

49 Robinson HE, O'Connell CM, Joseph KS et al. Maternal outcomes in pregnancies complicated by obesity. Obstet Gynecol 2005; 106: 1357-1364

50 Weiss JL, Malone FD, Emig D et al. Obesity, obstetric complications and cesarean delivery rate - a population-based screening study. Am J Obstet Gynecol 2004; 190: 1091-1097

51 Berger $\mathrm{H}$, Crane J, Farine $\mathrm{D}$ et al. Screening for gestational diabetes mellitus. J Obstet Gynaecol Can 2002; 24: 894-912

52 Wolfe HM, Sokol RJ, Martier SM et al. Maternal obesity: a potential source of error in sonographic prenatal diagnosis. Obstet Gynecol 1990; 76 (3 Pt 1): 339-342 
53 Nuthalapaty FS, Rouse DJ. The impact of obesity on obstetrical practice and outcome. Clin Obstet Gynecol 2004; 47: 898-913; discussion 980981

54 Anderson JL, Waller DK, Canfield MA et al. Maternal obesity, gestational diabetes, and central nervous system birth defects. Epidemiology 2005; 16: 87-92

55 Yeh J, Shelton JA. Association of pre-pregnancy maternal body mass and maternal weight gain to newborn outcomes in twin pregnancies. Acta Obstet Gynecol Scand 2007; 86: 1051-1057

56 Fox NS, Roman AS, Saltzman DH et al. Obesity and adverse pregnancy outcomes in twin pregnancies. J Matern Fetal Neonatal Med 2014; 27 : 355-359

57 Usha Kiran TS, Hemmadi S, Bethel J et al. Outcome of pregnancy in a woman with an increased body mass index. BJOG 2005; 112: 768-772

58 Bianco AT, Smilen SW, Davis Yet al. Pregnancy outcome and weight gain recommendations for the morbidly obese woman. Obstet Gynecol 1998; 91: 97-102

59 Dempsey JC, Ashiny Z, Qiu CF et al. Maternal pre-pregnancy overweight status and obesity as risk factors for cesarean delivery. J Matern Fetal Neonatal Med 2005; 17: 179-185

60 Steinfeld JD, Valentine S, Lerer T et al. Obesity-related complications of pregnancy vary by race. J Matern Fetal Med 2000; 9: 238-241

61 Kalache KD, Dückelmann AM, Michaelis SA et al. Transperineal ultrasound imaging in prolonged second stage of labor with occipitoanterior presenting fetuses: how well does the 'angle of progression' predict the mode of delivery? Ultrasound Obstet Gynecol 2009; 33: 326330

62 Perlow JH, Morgan MA. Massive maternal obesity and perioperative cesarean morbidity. Am J Obstet Gynecol 1994; 170: 560-565

63 Myles TD, Gooch J, Santolaya J. Obesity as an independent risk factor for infectious morbidity in patients who undergo cesarean delivery. Obstet Gynecol 2002; 100 (5 Pt 1): 959-964

64 Schneid-Kofman N, Sheiner E, Levy A et al. Risk factors for wound infection following cesarean deliveries. Int J Gynaecol Obstet 2005; 90: 1015

65 Durnwald CP, Ehrenberg HM, Mercer BM. The impact of maternal obesity and weight gain on vaginal birth after cesarean section success. Am J Obstet Gynecol 2004; 191: 954-957

66 Juhasz G, Gyamfi C, Gyamfi P et al. Effect of body mass index and excessive weight gain on success of vaginal birth after cesarean delivery. Obstet Gynecol 2005; 106: 741-746

67 Chauhan SP, Magann EF, Carroll CS et al. Mode of delivery for the morbidly obese with prior cesarean delivery: vaginal versus repeat cesarean section. Am J Obstet Gynecol 2001; 185: 349-354

68 Royal College of Obstetricians and Gynaecologists (RCOG). Caesarean section. London: RCOG; 2004

69 Goldani MZ, Barieri MA, da Silva AA et al. Cesarean section and increased body mass index in school children: two cohort studies from distinct socioeconomic background areas in Brazil. Nutr J 2013; 12: 104

70 Hermansson H, Hoppu $U$, Isolauri E. Elective caesarean section is associated with low adiponectin levels in cord blood. Neonatology 2014; 105: $172-174$

71 Maged $C$. The effect of mode of delivery on childhood obesity. Am J Obstet Gynecol 2014; 210 (Suppl. 1): 120; S77

72 Raban 0, Hadar E, Biron-Shental T et al. A comparison between electrical uterine monitoring, tocodynamometry and intra uterine pressure catheter for assessment of uterine activity during labor. Am J Obstet Gynecol 2014; 210 (Suppl. 1): 565; S273

73 Sheiner E, Levy A, Menes TS et al. Maternal obesity as an independent risk factor for caesarean delivery. Paediatr Perinat Epidemiol 2004; 18: 196-201

74 Jensen DM, Damm P, Sørensen B et al. Pregnancy outcome and prepregnancy body mass index in 2459 glucose-tolerant Danish women. Am J Obstet Gynecol 2003; 189: 239-244

75 Delpapa EH, Mueller-Heubach E. Pregnancy outcome following ultrasound diagnosis of macrosomia. Obstet Gynecol 1991; 78 (3 Pt 1): 340-343

76 Parry S, Severs CP, Sehdev HM et al. Ultrasonographic prediction of fetal macrosomia. Association with cesarean delivery. J Reprod Med 2000; 45: $17-22$

77 Sacks DA, Chen $W$. Estimating fetal weight in the management of macrosomia. Obstet Gynecol Surv 2000; 55: 229-239
78 Jacobsen AF, Skjeldestad FE, Sandset PM. Ante- and postnatal risk factors of venous thrombosis: a hospital-based case-control study. J Thromb Haemost 2008; 6: 905-912

79 Barnardo PD, Jenkins JG. Failed tracheal intubation in obstetrics: a 6year review in a UK region. Anaesthesia 2000; 55: 690-694

80 Hood DD, Dewan DM. Anesthetic and obstetric outcome in morbidly obese parturients. Anesthesiology 1993; 79: 1210-1218

81 Grau T, Bartusseck E, Conradi $R$ et al. Ultrasound imaging improves learning curves in obstetric epidural anesthesia: a preliminary study. Can J Anaesth 2003; 50: 1047-1050

82 Amir LH, Donath S. A systematic review of maternal obesity and breastfeeding intention, initiation and duration. BMC Pregnancy Childbirth 2007; 7: 9

83 Mok E, Multon C, Piguel L et al. Decreased full breastfeeding, altered practices, perceptions, and infant weight change of prepregnant obese women: a need for extra support. Pediatrics 2008; 121 : e1319-e1324

84 Rasmussen KM, Kjolhede CL. Prepregnant overweight and obesity diminish the prolactin response to suckling in the first week postpartum. Pediatrics 2004; 113: e465-e471

85 Dyson L, McCormick F, Renfrew MJ. Interventions for promoting the initiation of breastfeeding. Cochrane Database Syst Rev 2005; 2: CD001688

86 Paulson J, Mehta S, Sokol R et al. Maternal obesity and long-term cognitive function of offspring. Am J Obstet Gynecol 2014; 210 (Suppl. 1): 225; S446

87 Leermakers EA, Anglin K, Wing RR. Reducing postpartum weight retention through a correspondence intervention. Int J Obes Relat Metab Disord 1998; 22: 1103-1109

88 Lovelady CA, Garner KE, Moreno KL et al. The effect of weight loss in overweight, lactating women on the growth of their infants. $\mathrm{N}$ Engl J Med 2000; 342: 449-453

89 O'Toole ML, Sawicki MA, Artal R. Structured diet and physical activity prevent postpartum weight retention. J Womens Health (Larchmt) 2003; 12: 991-998

90 Amorim Adegboye AR, Linne YM. Diet or exercise, or both, for weight reduction in women after childbirth. Cochrane Database Syst Rev 2013; 7: CD005627

91 Siddik-Ahmad R, Garabedian M, Ianovich F et al. Gestational diabetes, obesity, and self perceived risk of type 2 diabetes. Am J Obstet Gynecol 2014; 210 (Suppl.): S168-S169

92 Bellamy L, Casas JP, Hingorani AD et al. Type 2 diabetes mellitus after gestational diabetes: a systematic review and meta-analysis. Lancet 2009; 373: 1773-1779

$93 \mathrm{Kim}$ C, Newton KM, Knopp RH. Gestational diabetes and the incidence of type 2 diabetes: a systematic review. Diabetes Care 2002; 25: 1862-1868

94 Colquitt J, Clegg A, Loveman E et al. Surgery for morbid obesity. Cochrane Database Syst Rev 2005; 4: CD003641

95 Weiss HG, Nehoda H, Labeck B et al. Pregnancies after adjustable gastric banding. Obes Surg 2001; 11: 303-306

$96 \mathrm{Kral} \mathrm{JG}$, Biron S, Simard S et al. Large maternal weight loss from obesity surgery prevents transmission of obesity to children who were followed for 2 to 18 years. Pediatrics 2006; 118: e1644-e1649

97 Willmer M, Berglind D, Sørensen TI et al. Surgically induced interpregnancy weight loss and prevalence of overweight and obesity in offspring. PLoS One 2013; 8: e82247

98 Astrup A, Rössner S, Van Gaal L et al. Effects of liraglutide in the treatment of obesity: a randomised, double-blind, placebo-controlled study. Lancet 2009; 374: 1606-1616

99 Foghsgaard S, Vedtofte L, Mathiesen ER et al. The effect of a glucagonlike peptide- 1 receptor agonist on glucose tolerance in women with previous gestational diabetes mellitus: protocol for an investigatorinitiated, randomised, placebo-controlled, double-blinded, parallel intervention trial. BMJ Open 2013; 3: e003834

100 Authority Clinical Negligence Scheme for Trusts. Maternity clinical risk management standards. NHS Litigation Authority; 2009

101 Knight-Agarwal CR, Kaur M, Williams LT et al. The views and attitudes of health professionals providing antenatal care to women with a high BMI: a qualitative research study. Women Birth 2013; DOI: 10.1016/j.wombi.2013.11.002

102 Sutherland G, Brown S, Yelland J. Applying a social disparities lens to obesity in pregnancy to inform efforts to intervene. Midwifery 2013; 29: $338-343$ 
103 Johnson M, Campbell F, Messina J et al. Weight management during pregnancy: a systematic review of qualitative evidence. Midwifery 2013; 29: 1287-1296

104 Wilkinson SA, Poad D, Stapleton H. Maternal overweight and obesity: a survey of clinicians' characteristics and attitudes, and their responses to their pregnant clients. BMC Pregnancy Childbirth 2013; 13: 117

105 Shub A, Huning EY, Campbell KJ et al. Pregnant women's knowledge of weight, weight gain, complications of obesity and weight management strategies in pregnancy. BMC Res Notes 2013; 6: 278
106 Cabrera Escobar MA, Veerman JL, Tollman SM et al. Evidence that a tax on sugar sweetened beverages reduces the obesity rate: a meta-analysis. BMC Public Health 2013; 13: 1072

107 Tripp N, Hainey K, Liu A et al. An emerging model of maternity care: Smartphone, midwife, doctor? Women Birth 2014; 27: 64-67

108 Denison FC, Norwood P, Bhattacharya S et al. Association between maternal body mass index during pregnancy, short-term morbidity, and increased health service costs: a population-based study. BJOG 2014; 121: $72-81$ 